\title{
Tecnología, Pos-humano, Des-humano
}

\author{
José M. Candela
}

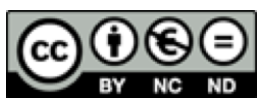

Esta obra está bajo una licencia Creative Commons

Reconocimiento-No comercial-Sin Obra Derivada 

Artículos

\title{
Tecnología, Pos-humano, Des-humano
}

\author{
José M. Candela \\ Universidad de Chile \\ candela.jm@gmail.com
}

Recibido: 16 de enero de 2015 Aprobado:18 de febrero de 2016

\section{Resumen}

El presente artículo intenta exponer de manera sintética el tema de la tecnología digital y sus implicancias en relación con el cuerpo, considerando este en sus manifestaciones, tanto cotidianas como escénicas. Con este fin, se abordan diversos aspectos en torno a la idea de la modificación del cuerpo material gracias a la tecnología, exponiendo para esto las perspectivas de lo pos-humano -la superación del cuerpo gracias a la tecnología- en contraposición a lo des-humano -la privación del propio cuerpo por parte de un poder panóptico. En esta dirección, el texto considera ópticas fenomenológicas, semánticas, políticas y tecnológicas del cuerpo, las que buscan realizar una discusión argumentativa de características dialécticas. Finalmente, el ensayo propone posibles (y necesarias) áreas de producción de conocimiento, derivadas de las reflexiones expuestas.

Palabras clave: pos-humano, ciborg, panoptismo, realidad mixta, arte interactivo, interfaz corporal.

\begin{abstract}
This paper synthetically attempts to describe the topic of digital technology and its implications relative to body, considering it in their everyday life but also at performing arts. With this finality, it addresses various aspects and implications around the idea of the material body modification through technology, exposing for this the prospects of post-human - the body outstripped by technology -opposed to dis-human - the body deprivation by a panoptic power. In this direction, the text considers body in its phenomenological, semantic, political and technological aspects, seeking to construct a dialectical argumentative discussion. Finally, this essay proposes possibles (and necessaries) knowledge production areas, derived from the foregoing considerations.
\end{abstract}

Key words: post-human, cyborg, panoptism, mixed reality, interactive art, body interface. 


\section{Artículos}

\section{Introducción}

La tecnología ha estado, desde siempre, vinculada a la historia humana. Sin embargo, la idea de "revolución tecnológica" frecuentemente expuesta como un signo de contemporaneidad, trae consigo cambios en la vida del hombre en multiplicidad de niveles; muchos de ellos podrían considerarse paradigmáticos. De forma particular, resulta interesante observar el vínculo que construyen tecnología y cuerpo (el cuerpo cotidiano, pero también el cuerpo escénico). En este campo general, se intentará, mediante el siguiente artículo, exponer las posibles consecuencias que surgen de esta conjunción, considerando distintos panoramas e implicancias relacionados con el cuerpo y su modificación. Para ello, se tomaron en cuenta las figuras contrapuestas de los conceptos de pos-humano (superación del cuerpo) versus des-humano (privación de humanidad producto del abandono del cuerpo). La discusión se presenta desde cuatro perspectivas: cuerpo fenomenológico, cuerpo significante, biopolítica, y cuerpo virtual (cuerpo cyborg).

\section{Tecnología, pos-humano y des-humano}

El uso de la tecnología digital en su relación con el cuerpo comprueba una doble dimensionalidad de características dialécticas. Si bien encarna la evolución del cuerpo hacia un pos-humano tecnológico y a una posible emancipación, -provocando así una modificación fenomenológica del cuerpo-, también despliega, gracias a la misma tecnología, un tipo de vigilancia panóptica (de los observados, de los que vigilan), que la evolución tecnológica perfecciona y que el poder económico ejerce. En líneas generales, se desarrolla para la obtención de más y mejor información, y finalmente, de mayor productividad.

La noción de pos-humano implica una situación de trascendencia del cuerpo por sobre su certeza cartesiana (cogito ergo sum), una liberación de este, de sus limitaciones conforme a un status quo positivista:

La idea de que el cuerpo está sujeto a una clausura sistemática pervive a través de la historia del pensamiento europeo que inscribe el cuerpo en unas coordenadas invariablemente espaciales y geométricas. La anatomía como cárcel es, pues, el modelo del cuerpo pos-humano, y el imperativo de trascenderla, la nueva aspiración de esta época. (Aguilar, 2008, p.129)

En efecto, los avances tecnológicos, y particularmente los computacionales, han ido posibilitando de manera creciente una modificación tecnológica de la organización corpórea como materialidad. Este pos-humano tecnológico se articula con la idea de superación y transformación refundacional de lo humano en tanto cuerpo.

Diseminada en la cultura popular como cibercultura y explorada también en el arte corporal actual, la idea de pos-humano quiere significar el universo de posibilidades que la tecnología ofrece a un cuerpo que, en la unión de la carne y el metal, promete una renovación radical de la experiencia subjetiva del mundo y de la vida. (Mejía, 2005, p.15) 
Esto posibilita una emancipación del cuerpo, una liberación del examen vigilante al que es sometido por parte de un poder histórico e invisible, superando su lógica binaria, eurocentrista y patriarcal.

Considerando lo anterior, resulta interesante preguntarse, en primera instancia, qué sucede entre el cuerpo en escena y su "prolongación" tecnológica (visual y sonora). En respuesta a esta interrogante, según Mark Hansen, crean, cuerpo y sonido una nueva dimensión audiovisual, una "Realidad Mixta":

[...] el paradigma de la Realidad Mixta radicalmente reconfigura un rasgo que ha caracterizado la Realidad Virtual de su protoorigen (primer origen) como la fantasía representacionalista por excelencia. Es decir, un deseo de una completa convergencia con la percepción natural: En lugar de concebir lo virtual como un simulacro técnico o la inmersión en un mundo de fantasía autocontenido, el paradigma de Realidad Mixta lo trata simplemente como un ámbito más entre otros, que puede ser accedido a través de la percepción corporizada o la enacción (Varela). De este modo el énfasis está menos en el contenido de lo virtual y más en la forma de acceder a ello, menos en lo que se percibe en el mundo y más en como uno llega a percibirlo en primer lugar. (Hansen, 2006, p.5)

La Realidad Mixta puede llevarnos a un nuevo conocimiento, es decir, siguiendo a Hasen, es posible -desde la práctica y metodología artística - implementar una estrategia que permita testimoniar un nuevo tipo de conocimiento. En este marco, resulta especialmente atractivo observar lo que sucede con el uso de una interfaz (por ejemplo, una que funcione a través de cámara, micrófono y software) que interactúe "sensiblemente" con el cuerpo escénico a través del tiempo, devolviendo imágenes visuales y/o sonoras de este cuerpo. Estos usos tienen el rédito de incentivar la generación de signos kinéticos a nivel poiético y estésico, los cuales producen un fenómeno de comunicación/percepción particular. Dicha particularidad permite una interacción más creativa y menos mecánica entre el cuerpo en escena, (y sus espectadores) y la interfaz (con sus extensiones visual y sonora); además, acerca la situación artística al participante, convirtiéndolo en un co-creador:

Cuanto más frecuentemente pasa la percepción del orden de la presencia al orden de la representación, es decir, de procesos de percepción y de generación de significado «azarosos» a procesos predecibles, mayor es el grado de imprevisibilidad general y más intensamente se centra la atención del sujeto perceptor en el proceso de percepción en sí. Se hace cada vez más consciente de que los significados no le son transmitidos, sino que es él quien los genera y que, por lo tanto, podría haber generado otros significados muy distintos. (Fischer Lichte, 2011, p. 299)

Existe en este proceso perceptivo “...a partir de la interacción,..." una modificación fenoménica en el cuerpo presente, gracias al adiestramiento del cuerpo a la nueva respuesta. De esta manera, se transforma la 


\section{Artículos}

interfaz en un extensión del cuerpo, un suplemento que altera nuestro percibir $y$, por ende, nuestro ser, aquí y ahora.

[...] el hábito no consiste en interpretar las presiones del bastón en la mano [de un ciego] como signos de ciertas posiciones de bastón, y éstas, como signos de un objeto exterior, ya que el hábito nos dispensa de hacerlo. Las presiones en la mano y el bastón no son ya dados, el bastón no es ya un objeto que el ciego percibiría, sino un instrumento con el que percibe. Es un apéndice del cuerpo, una extensión de la síntesis corpórea. (Merleau Ponty, 1997, p. 169)

El problema es que esta eficiencia perceptiva puede también ser manejada. La videocámara y el micrófono hoy representan la expansión del cuerpo hacia un nuevo espacio (visual y sonoro), y por lo tanto, la modificación de este, pues "[...] ser cuerpo es estar anudado a un cierto mundo, [...] y nuestro cuerpo no está, ante todo, en el espacio: es del espacio" (Merleau Ponty, 1997, p.165). No obstante, también representan la exclusión, desde un poder panóptico, de la autonomía del propio cuerpo y de la voluntad ejercida por sobre el cuerpo individual, de tal manera que puede incidir directamente en las decisiones de ese cuerpo ajeno y en sus manifestaciones como sujeto social.

La anterior exclusión no es en absoluto ingenua. Al estar aislados de la tecnología pero no de los usos tecnológicos, los cuerpos se convierten en potencial material manipulable por parte de quien domina la tecnología.
El panoptismo aparece, entonces, como una segunda dimensión, que se contrapone a la tesis de la emancipación del pos-humano tecnológico. Citando a Foucault:"La vigilancia pasa a ser un operador económico decisivo, en la medida en que es a la vez una pieza interna en el aparato de producción y un engranaje especificado del poder disciplinario" (Foucault, 2002, p.180) . en este sentido, la vigilancia actúa como limitación del cuerpo (para obtener su control) y no como expansión de este.

La videocámara y el micrófono -que pueden significar la concreción de una Realidad Mixta liberadora- son, en la actualidad, fuertemente significantes de un poder oculto, observador, manipulador, que nos usa como masa útil para sus propios intereses. Son símbolos de una especialización contemporánea: la tecnología panóptica:

La mirada panóptica cuenta con numerosos aliados que garantizan su eficacia. Los ojos que vigilan se han multiplicado, para ello los medios de comunicación, las telecomunicaciones y la computación han contribuido a afirmar esa fuerza de homogeneización que envuelve a los individuos en las sociedades contemporáneas. [...] Las imágenes captadas por las cámaras de video y reproducidas en monitores han impuesto un cambio en la relación de los individuos con el mundo, pero al mismo tiempo han multiplicado la mirada. La mirada se vuelve múltiple, los mecanismos panópticos del poder se intensifican y extienden sus redes atravesando a los individuos siendo vulnerados en su intimidad. (García, 2009, párrs. 20-22) 
En esta multiplicación, pueden ser vigilados todos, incluso los que vigilan. La privación de lo humano se acrecienta, y un des-humano tecnológico - un cuerpo que se ve despojado de sus cualidades humanas debido a la presencia de mecanismos tecnológicos de control de características panópticas - toma el lugar de un cuerpo independiente y emancipado. Esta correspondencia dialéctica en el cuerpo tecnológico (pos-humano y des-humano) devela un lugar de reflexión políticamente necesario, para la detección y superación de estos contrapuestos.

Desde cierta perspectiva, un mundo de cyborgs es la última imposición de un sistema de control en el planeta. Es la última de las abstracciones inherentes a un apocalipsis de Guerra de Galaxias emprendida en nombre de la defensa nacional, la apropiación final de los cuerpos de las mujeres en una masculinista orgia de guerra. Desde otra perspectiva, un mundo así, podría tratarse de realidades sociales y corporales vividas, en las que la gente no tiene miedo de su parentesco con animales y máquinas; ni de identidades permanentemente parciales; ni de puntos de vista contradictorios. La lucha política consiste en ver desde las dos perspectivas, ya que cada una de ellas revela al mismo tiempo, tanto las dominaciones como las posibilidades inimaginables desde otro lugar estratégico. (Haraway, 1991, p.8 [traducción propia])

Es por estos motivos que se hace necesario una profunda reflexión que devele un mayor conocimiento sobre este transformar dialéctico pos-humano/des-humano: el cuerpo en el centro de sí mismo, conciente y crítico frente a las posibilidades proyectivas, y atento a las nuevas formas de panoptismo que buscan controlarlo. Y sobre todo, partidario, responsable y solidario de su propio devenir (y de lo que de este devenga).

\section{Una experiencia performática}

El día 4 de julio del año 2013, en la Sala Blanca y en la Sala 1 del Campus Oriente de la Pontificia Universidad Católica de Chile, se llevó a cabo la performance "Tecnología/ Pos-humano/Des-humano", con la colaboración de la intérprete corporal Carola Méndez. En esta intervención corpóreo-sonoro-visual del espacio, el uso de la tecnología digital y su relación con el cuerpo, llevaron a la práctica la doble dimensionalidad arriba señalada, con intenciones reflexivas. Ambas salas pudieron ser visitadas libremente, en cualquier momento, por los espetadores de la performance. En la Sala Blanca, se podía observar (audioespectar) la emergencia de una proyección del cuerpo hacia el mundo cyborg (híbrido de máquina y organismo) gracias a la instalación de un micrófono y una videocámara que expandían el cuerpo en movimiento de la intérprete (que realizaba una improvisación danzaria en lenguaje contemporáneo) hacia el campo visual (mediante la proyección de variaciones en tiempo real de los movimientos de la bailarina) y sonoro (creando música electroacústica en tiempo real, la que adquiría intensidades rítmicas y tímbricas en directa 


\section{Artículos}

\section{Fotografía 1}

Performance "Tecnología/Pos-humano/Des-humano", Sala Blanca. En la foto se puede ver a la bailarina y su proyección modificada en tiempo real.

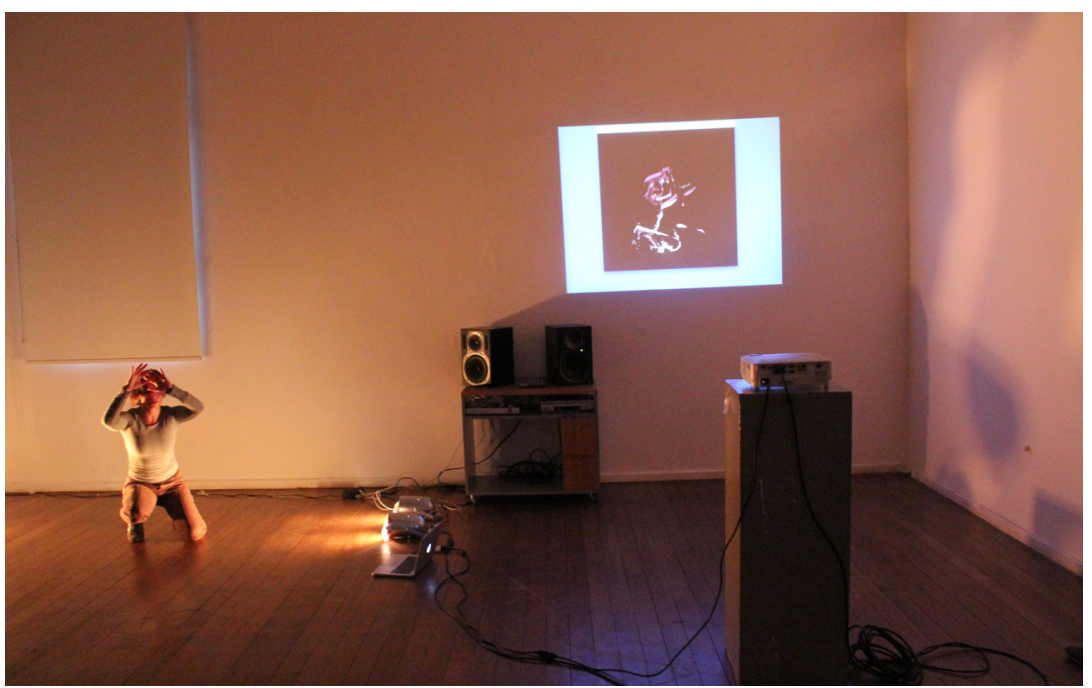

Fuente: Jose M. Candela

\section{Fotografía 2}

Performance "Tecnología/Pos-humano/Des-humano", Sala Blanca. En la foto se puede ver a la bailarina y su proyección modificada en tiempo real.

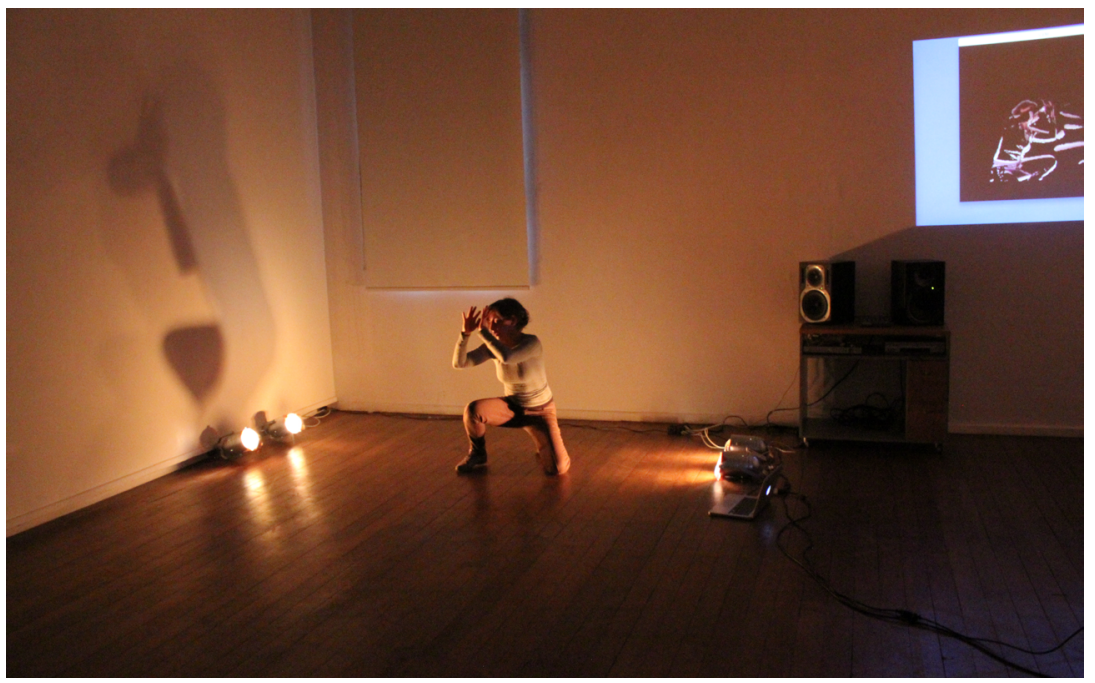

Fuente: Jose M. Candela 


\section{Fotografía 3}

Performance "Tecnología/Pos-humano/Des-humano", Sala Blanca. En la foto se puede ver a la bailarina y su proyección modificada en tiempo real.

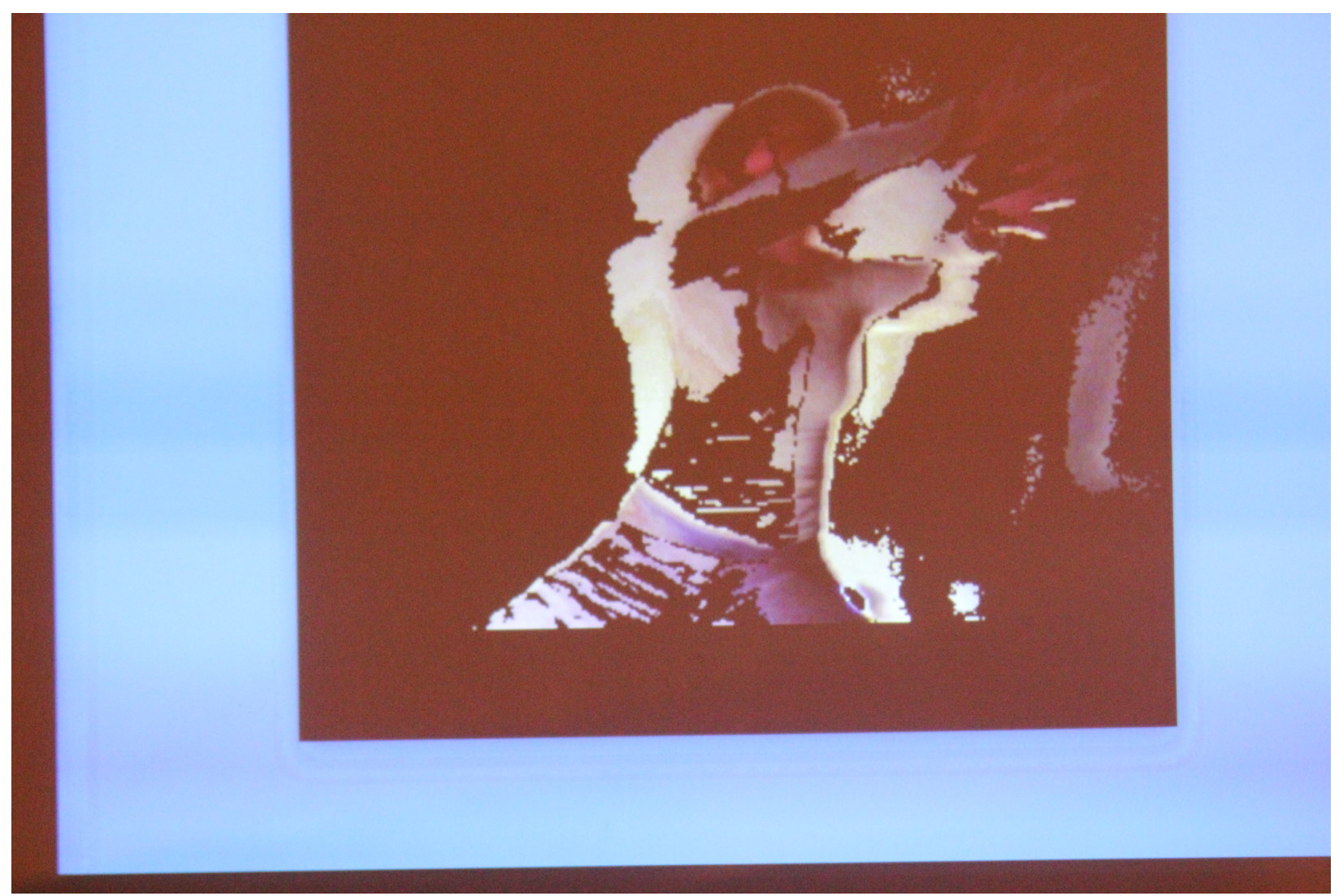

Fuente: Jose M. Candela

relación con la intensidad de los movimientos de la intérprete).

Esta expansión podía ser observada y escuchada por la intérprete y, por lo tanto, podía dialogar con ella, lo que finalmente provocaba una modificación fenomenológica de su actuar durante su experiencia. En síntesis, la interfaz se transformaba en prótesis corpórea, y el resultado podía ser entendido desde el concepto de cuerpo extendido. Sin embargo, en la Sala 1 se observaba cómo, con una tecnología similar, se conformaba un tipo de vigilancia panóptica, a través de 3 proyecciones en 3 pantallas distintas. En una se dejaba ver la proyección de una videocámara de vigilancia situada enmascaradamente en la Sala Blanca (lugar de la performance), donde se podía observar lo que sucedía tanto con la bailarina y su extensión corpórea, como con el público visitante. 


\section{Artículos}

\section{Fotografía 4}

Performance "Tecnología/Pos-humano/Des-humano", Sala Blanca. En la foto se puede ver a la bailarina y su proyección modificada en tiempo real.

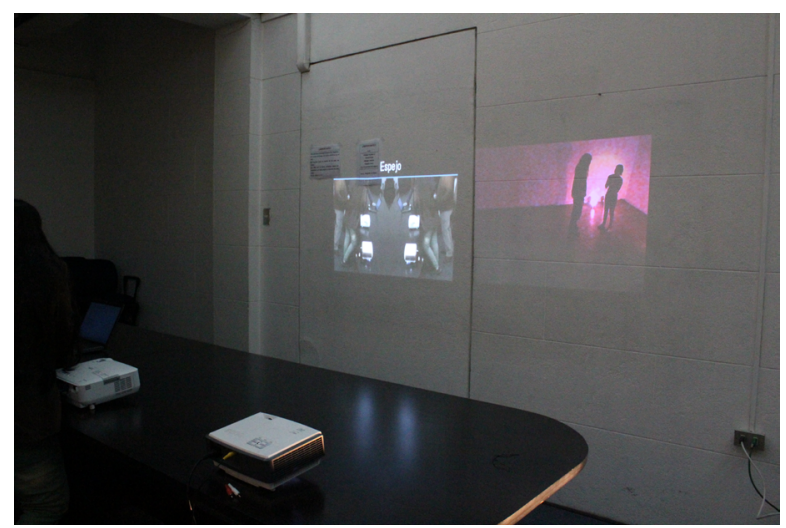

Fuente: Jose M. Candela

En otra proyección se podía ver un bucle sinfin con fichas de datos y fotos recopiladas de los propios visitantes (su construcción rápida fue posible pues la mayoría de los visitantes estaban en las bases de datos de la universidad); finalmente, la tercera pantalla proyectaba una videocámara situada en la misma Sala 1, que captaba todo lo que ocurría en este lugar y que, de algún modo, intentaba dejar planteada una paradoja: el testimonio panóptico del panoptismo ejercido por los visitantes de la sala.

La dialéctica que se plantea es clara: con lo primero, se presenta la evolución del cuerpo hacia un pos-humano tecnológico y a una posible emancipación; con lo segundo, se despliega un tipo de vigilancia en distintos niveles (vigilancia de los observados, vigilancia de los que vigilan). Una vigilancia que, como hemos indicado, la evolución tecnológica permite y que, de manera muy similar a la presentada en la performance, el poder económico ejerce para la obtención de más y mejor información, y finalmente, de mayor productividad.

\section{Conclusiones}

He intentado referirme a un fenómeno particular en el vínculo entre cuerpo y tecnología: la reciprocidad dialéctica presente en los conceptos de pos-humano y des-humano. Para ello, he querido enfatizar los aspectos fenomenológicos, semánticos y políticos vinculados al cuerpo tecnológico, pero también la expoliación de su condición humana por parte de esta misma tecnología, provocada por una vigilancia de características panópticas, que a su vez, permite un creciente dominio del cuerpo por parte de un otro que se localiza en el campo del poder económico. Ahora bien, siendo consecuentes con una búsqueda emancipadora del cuerpo, se hace necesario profundizar esta disputa pos-humano/ des-humano. Un plano que resultaría interesante recorrer con dedicación, guarda relación con el tipo de modificaciones a que se ve sometido el cuerpo en su proceso de adiestramiento frente a una tecnología dialogante, pues en ese adiestramiento -en ese hacernos eficientes ante un significado de características orgánicas sobre esta realidad mixta- existe un conocimiento nuevo, el cual es sensible en términos dialécticos a 
la dualidad aquí planteada.

También se hace necesaria la realización de una investigación exhaustiva con el fin de describir “...,de la mejor manera posible,..." los modos de vigilancia panóptica que la tecnología actualmente permite e, incluso, considerando la posibilidad de conformar una tipología que desenmascare este nuevo panoptismo. De esta forma, profundizando el conocimiento en torno a los temas derivados de la oposición del cuerpo pos-humano y des-humano, se podrá aspirar a su superación y, finalmente, a una verdadera emancipación del cuerpo.

\section{Referencias}

Aguilar G., T. (2008). Ontología Cyborg. El cuerpo en la nueva sociedad tecnológica. Barcelona: Gedisa.

Fischer-Lichte, E. (2012). Estética de lo performativo. Madrid: Abada Editores.
Foucault, M. (2002). Vigilar y Castigar. Nacimiento de la prisión. Buenos Aires: Siglo XXI.

García, R. (2009). El panoptismo: nuevas formas de control social. Contribuciones a las Ciencias Sociales, 6(2). Recuperado de http:// www.eumed.net/rev/cccss/06/rgj2.htm

Hansen, M. (2006). Bodies in code. Interfaces with digital media. London \& N.Y.: Routledege.

Haraway, D. (1991). Manifiesto Cyborg. Ciencia, Tecnología y Feminismo Socialista Finales.

Mejía, I. (2005). El cuerpo post-humano: en el arte y la cultura contemporánea. México: UNAM.

Merleau Ponty, M. (1997) Fenomenlogía de la percepeción. Barcelona: Ediciones Península. 